\title{
Non-conventional yeast-promoted biotransformation for the production of flavor compounds
}

\author{
Luca Forti ${ }^{1 *}$, Maria Rita Cramarossa ${ }^{1}$, Sara Filippucci $^{2}$, Giorgia Tasselli $^{2}$, Benedetta \\ Turchetti² $^{2}$ Pietro Buzzini ${ }^{2 *}$ \\ ${ }^{1}$ Department of Life Sciences, University of Modena \& Reggio Emilia, via G. Campi 103, Modena \\ 41125, Italy; E-Mail: luca.forti@unimore.it \\ ${ }^{2}$ Department of Agricultural, Environmental and Food Sciences, Industrial Yeasts Collection \\ DBVPG, University of Perugia, Borgo XX Giugno 74, Perugia 06121, Italy; E-Mail: \\ pietro.buzzini@unipg.it \\ * Authors to whom correspondence should be addressed; E-Mails: luca.forti@unimore.it (L.F.); \\ pietro.buzzini@unipg.it (P.B.); Tel.: +39-059-2058591 (L.F.); Tel.: +39-075-5856455 (P.B.).
}

Keywords: Non-conventional yeasts; biotransformation; biocatalysis; flavors; aroma; volatile organic compounds (VOCs); volatile sulfur compounds (VSCs)

\begin{abstract}
The rising consumer demand for "natural" foodstuffs have encouraged a growing part of both Academic and Industrial scientific community to develop novel biocatalysts for producing flavouring molecules. In this context, non-conventional yeasts (NCYs) have attracted increasing interest due to their biochemical characteristics and potential applications, being able to produce aroma compounds from a variety of carbon sources, including sugars, alkanes, plant oils, starch hydrolysates, ethanol, and glycerol. Apart from classical fermentation processes (de novo synthesis), bioconversion of appropriate precursor compounds are also being developed to produce food aromas.

An overview on the potential of NCYs whole cell for producing food flavors by biotransformation is illustrated in this chapter by a discussion of the production of different class of compounds, namely Alcohols, Aldehydes, Ketones Lactones, Terpenes and Terpenoids, Alkenes, Phenols, and Sulphur compounds.
\end{abstract}

\section{Introduction}

Flavors play an essential role in the quality perception of food and beverages: whereas the nonvolatile compounds contribute mainly to the taste, the volatile ones influence both taste and aroma. 
Numerous compounds may be responsible for the aroma of the food products, such as ketones, aldehydes, alcohols, fatty acids, esters, lactones, terpenes, aromatic and sulfur compounds (Table $1)$.

\section{<Insert table 1 here>}

Nowadays, most of the flavoring compounds are produced via chemical synthesis or by extraction from natural materials, which still represents the cheaper technology for their production. An alternative route for flavors synthesis is based on de novo microbial process (fermentation) or on biotransformation of suitable precursors using microbial cells or enzymes (biocatalysis) (Longo et al. 2006, Janssens et al. 1992, Krings and Berger 1998, Vandamme and Soetaert 2002, Aguedo et al. 2004). Thus, the rising consumer demand for "natural" foodstuffs have boosted a growing part of both Academic and Industrial scientific community to develop novel biocatalysts for producing these flavouring molecules (Krings and Berger 1998, Lomascolo et al. 1999, Brenna et al. 2011). Indeed, according to EU regulations, natural flavours are defined as substances corresponding to substances that are naturally present and have been 'identified in nature': as stated by the European Food Safety Autority (EFSA), a flavor is 'identified in nature' when "it has been identified in materials of plant, animal, microbiological, or mineral origin, and/or it has been identified in food in the raw state or processed or partly processed fo human consumption" (Demyttenaere 2012). Thus, the products obtained through microbial or enzymatic processes and that the precursor and product can be found in nature or are part of traditional foods can be considered as 'natural'.

Although the biocatalytic ability of yeasts is a well-known phenomenon, and some processes using yeast whole cells for selected biotransformation at the industrial level have been reviewed (Johnson and Echavarri-Erasun 2011), the studies aimed at evaluating the potential of the so-called non-conventional yeasts as biocatalysts have never been substantially reviewed so far.

In this chapter, we will review the use of non-conventional yeasts for producing food-grade flavor compounds via biocatalysis.

\subsection{Non-conventional yeasts (NCYs) as biocatalysts}

Yeasts are unanimously considered as key players of a variety of traditional (i.e. fermented foods and beverages) and innovative (i.e. high-value bulk and fine chemicals) processes. The impact of yeast biotechnology on human activities has been extensively documented (Domínguez et al. 1998, Walker 1998, Flores et al. 2000, Johnson and Echavarri-Erasun 2011). Many of these studies are 
closely related with the yeast Saccharomyces cerevisiae (otherwise labeled as baker's yeast), which is traditionally used for producing bread, beer, wine, a number of ethnic fermented foods and beverages in Asia, Africa and South America, and some important industrial commodities (e.g. ethanol as additive for biofuels) (Walker 1998).

The wide dissemination of the results from those studies and industrial applications has determined that to most people, including a not negligible number of (micro)biologists, this species was erroneously taken as an example (and model) for studying the whole diversity of yeast world. On the contrary, in recent decades the taxonomic, physiologic and metabolic diversity of the so-called "non-conventional yeasts" (NCYs) have been deeply investigated (Wolf et al. 2003, Sibirny and Scheffers 2002, Buzzini and Vaughan-Martini 2006.). There is no generally accepted definition on NCYs. Even though a number of scientists includes a few additional species (namely, at least Schizosaccharomyces pombe and Kluyveromyces lactis) into the group of "conventional yeasts" (CYs), many other consider NCYs as synonymous of "non-Saccharomyces" yeasts. As early reported by Sibirny and Scheffers (2002) "there is no generally accepted definition on NCYs". A number of scientists consider NCYs simply as synonymous of "non-Saccharomyces" yeasts, while many others include the two species Schizosaccharomyces pombe and Kluyveromyces lactis into the group of "conventional yeasts" (CYs). Because of the above definitions result sometimes incomplete and indeterminate, the same authors (Sibirny and Scheffers 2002) also concluded that, since an increasing number of NCYs is gaining importance in fundamental and applied microbiological sciences, the term NCYs is gradually losing both significance and usefulness. Beyond any definition, because of the current yeast taxonomy accounts for more than 130 ascomycetous and basidiomycetous genera and over 1,600 species, NCYs represent the vast majority of yeast diversity so far described (Kurtzman et al. 2011). Undoubtedly, this huge yeast diversity includes many species possessing useful, and sometimes uncommon, metabolic aptitudes that could be potentially exploited in both food and no-food industry (Johnson et al. 2011, Sibirny and Scheffers 2002, Spencer et al. 2002).

Demands for enhancing both productivity and efficiency of biotechnological processes from wider substrate range, production of novel molecules sometimes due to change of consumer preferences can lead to a great interest in further enhancing the number of NCYs exploited by industry (Steensels et al. 2014).

\subsection{Definition of biocatalysis and their impact on the production of flavors}


Biocatalysis may be defined as "a process that describes a reaction, or a set of simultaneous reactions, in which a pre-formed precursor molecule is converted using enzymes and/or whole cells, or combinations thereof, either free or immobilized" (Straathof et al. 2002), and sums up both biotrasformations and enzyme catalysis.

The high specificity and selectivity expressed by biocatalysts, and the possibility to use "environmental-friendly" conditions (e.g. solvent-free approaches, low working temperatures and pressures, and waste reduction) together with the possible reduction of the number of steps in a synthetic route actually justify the increasing use of biocatalysts in modern chemical processes. (Matsuda et al. 2009, Bastos Borges et al. 2009, Patel 2011, Faber 2004).

Isolated whole cells are often preferable than purified enzymes, because they are more convenient and stable, with no need for costly purification and coenzyme addition. In fact, although enzymes are considered as powerful tools, particularly for single step biotransformation, the number of free or immobilized enzymes commercially available on the market is still quite limited, particularly for some types of uncommon substrates. Moreover, when the enzymes are kept within their natural environment (i.e. cell cytoplasm) lesser inactivation usually occurs (Liese et al. 2006).

In recent years, biocatalysis has increasingly been investigated as promising manufacturing technique for food-grade flavors production. This is essentially justified by two reasons: firstly, biocatalysis sometimes allow the production of regio- and stereoselective compounds under mild conditions; secondly, the use of cell biocatalysts is unanimously considered a lesser pollutant technology. Accordingly, molecules obtained by such bioprocesses can be labeled as natural, and all volatile organic compounds (VOCs) obtained from living cells, including microorganisms, are labeled as GRAS (Generally Recognized As Safe) (Lomascolo et al. 1999). As a result, the biocatalytic potential of GRAS microorganisms (in particular, the use of whole cells for obtaining specific molecules) has attracted considerable interest.

\section{Biocatalytic production of flavours by NCYs}

\subsection{Aldehydes, ketones and alcohols}

Volatile C6- and C9-aldehydes and -alcohols are compounds that are responsible for the green notes characteristic flavors of fruits, vegetables and green leaves (Buchhaupt et al. 2012), and comprise hexanal, (3Z)- and (2E)-hexenal, (3Z)- and (2E)-nonenal, (3Z,6Z)- and (2E,6Z)nonadienal, and their corresponding alcohols, such as hexanol, (2E)- and (3Z)-hexenol (Buchhaupt et al. 2012). Leaf aldehyde, (2E)-hexenal, and leaf alcohol, (3Z)-hexenol, are considered to be the most valuable ones exhibiting various flavor applications and higher stability (Gigot et al. 2012). 
Early studies on the biotransformation of C precursors to aldehydes dated back to 1980s. Armstrong et al. (1984) found that an ethanol-adapted Candida utilis (anamorphic state of Lindnera jadinii) efficiently converted ethanol to acetaldehyde. A study reported the conversion of (Z)-3-hexenal into the corresponding (Z)-3-hexenol (Fig.1) by Wickerhamomyces anomalus (former Pichia anomala). Conversion yields higher than $90 \%$ were also obtained by directly conducting the reaction in the medium where (Z)-3-hexenal is produced by the action of lipoxygenase and hydroperoxide lyase on linolenic acid (Fauconnier et al., 1999).

\section{<Insert figure 1 here>}

More recently, a few ketoreductases isolated from NCYs exhibiting broad substrate range and high selectivity on ketone reduction chemistry have been studied (Faber 2004, Moore et al. 2007). They exhibited broad substrate range and high selectivity on ketone reduction chemistry, thus making biocatalysis the general method of choice for ketone reductions (Moore et al., 2007). Nicaud et al. (2002) studied the introduction of multiple fatty acid hydroperoxide (HPO) lyase genes into Yarrowia lipolytica genome for increasing its aptitude towards fed-batch cultivation and inducing highest production of HPO lyase activity and, consequently, the production of high quantities of C6-aldehydes via biocatalysis (Nicaud et al. 2002, Bourel et al. 2004).

Furaneol ${ }^{\circledR}$ (2,5-dimethyl-4-hydroxy-3(2H)-furanone - DMHF) is an volatile ketone, exhibiting strawberry flavour in dilute solutions and caramel-like flavour in concentrates. Furanones occur in many fruits (e.g. pineapple, strawberries, mangoes, raspberries), but also in certain microbial cultures and in soy sauce. It is also formed by the chemical reaction of sugars with amines during the Maillard reaction. A study reported that Zygosaccharomyces rouxii is able to form DMHF via D-fructose-1,6-diphosphate metabolism (Dahlen et al. 2001).

The flavoring compounds 2-phenylethanol (and its derivative 2-phenylethylacetate) are widely applied in food industries (Hua and Xu 2011), and can be produced from L-phenylalanine via batch and fed-batch biocatalysis by whole cells of Kluyveromyces marxianus (Etschmann et al. 2005, Etschmann and Schrader 2006, Gao and Daugulis 2009). The use of an organic phase to make easy downstream processing steps made fed-batch approach an attractive and cheap alternative to current industrial processes (Etschmann et al. 2005, Etschmann and Schrader 2006). More recently, Gao and Daugulis (2009) used a solid-liquid two-phase partition bioreactor system to reduce the aqueous 2-phenylethanol concentration to non-inhibitory levels and to allow an in situ product removal technique. A final 2-phenylethanol concentration of $20.4 \mathrm{~g} / \mathrm{L}$ was achieved (with $1.4 \mathrm{~g} / \mathrm{L}$ in the aqueous and $97 \mathrm{~g} / \mathrm{L}$ in the polymer phase) (Gao and Daugulis 2009). An alternative process for 
producing 2-phenylethanol from L-phenylalanine via biocatalysis was the Ehrlich pathway (Hua and $\mathrm{Xu} 2011)$.

In the last fifteen years, a number of studies described the optimal conditions for producing 2phenylethanol via biotransformation processes: yields from 0.5 to $5.6 \mathrm{~g} / \mathrm{L}$ were reported (Fabre et al. 1998, Huang et al. 2000, Huang et al. 2001, Etschmann et al. 2004, Garavaglia et al. 2007). The production of other food-grade alcohols via biocatalysis was recently studied. Andreu and Del Olmo (2014) described the use of whole cells of $K$. marxianus and L. jadinii (former Pichia jardinii) as biocatalysts for producing the chiral products derived from the aldol reaction between acetone and some aromatic aldehydes, as well as the chiral 1,3-diols deriving from their reduction. The resolution of the racemic starting material and the recovery of the aldol with the $S$ configuration was sometime possible using $K$. marxianus whole cells. Both species showed complementary enantioselectivity.

\subsection{Lactones}

Lactones are cyclic esters of primary $\gamma$ - and $\delta$-hydroxyacids: they are currently found in foods and beverage, and contribute to change their taste and flavor. Accordingly, the industry uses some of them, in particular $\gamma$-lactones as flavoring ingredients in many fruity aromatic foods (RomeroGuido et al. 2011). Although many synthetic $\gamma$-lactones are at present still utilized as flavoring additives, the consumer request is nowadays orienting to the use of natural flavors. this tendency increased the interest (and consequently the studies) for the production of $\gamma$-lactones via biocatalysis. Hence, $\gamma$-decalactone and $\gamma$-dodecalactone have been produced using free fatty acids, hydroxyl fatty acids, or oils as precursors through several enzymatic steps that catalyze their $\gamma$ oxidation (Krings and Berger 1998, An et al. 2013). Some high yield biotransformation used efficient NCYs for producing $\gamma$-lactones were developed (Kondo et al. 2000, Lee et al. 2004, de Carvalho 2011).

$\gamma$-Dodecalactone (responsible for a peach-like aroma) is a food-grade compound presently used as an aroma or taste ingredient of foods, chewing gums, toothpastes, cosmetics, pharmaceutics, cigarettes, soaps, and perfumes (Farbood et al. 1998, Karagül-Yüceer et al. 2001, Pino and Marbot 2001, Herianus et al. 2003, Elss et al. 2005, Nunes et al. 2008). An et al. (2013) developed a process for biotransforming oleic acid into $\gamma$-dodecalactone catalyzed by permeabilized cells of Waltomyces lipofer (now Lipomyces lipofer) with a conversion yield of $76 \%$. The of ricinoleic acid to $\gamma$ decalactone was also studied. The species Sporobolomyces odorus (now Sporobolomyces salmonicolor) was found to be able to convert castor oil (or its derivatives) to $\gamma$-decalactone (Dufossé et al. 1998). 
The species $Y$. lipolytica was broadly studied for its capability to produce lactones via biocatalysis. Groguenin et al. (2004) reported that this ascomycetous yeast synthesizes five acyl-CoA oxidases (Aox1p to 5), that catalyze the first of $\beta$-oxidation step. the same Authors ey constructed an overproducing that gave 10 times more $\gamma$-decalactone than the wild type. In contrast, EscamillaGarcia et al. (2007) optimized the production of $\gamma$-decalactone by $Y$. lipolytica using an experimental design (variables: $\mathrm{pH}$ and aeration conditions): $496 \mathrm{mg} / \mathrm{L}$ of $\gamma$-decalactone were obtained at $\mathrm{pH}$ around 5 and increased at low aeration. On the contrary, $660 \mathrm{mg} / \mathrm{L}$ of 3-hydroxy- $\gamma$ decalactone were accumulated at low $\mathrm{pH}$ and high aeration, thus postulating that hydroxylation of $\gamma$-decalactone was essentially oxygen-dependent (Escamilla-Garcia et al., 2009). More recently, Braga and Belo (2015) studied the production of $\gamma$-decalactone from ricinoleic acid by whole cells of $Y$. lipolytica in batch and fed-batch: a high $\gamma$-decalactone productivity $(215 \mathrm{mg} / \mathrm{L} \cdot \mathrm{h})$ was found (Fig.2). These interesting results suggest that these two strategies could be good alternatives for industrial production processes.

\section{<Insert figure 2 here>}

Likewise, Kang et al., (2016) produced $\delta$-decalactone from linoleic acid by one-pot reaction of enzymatic hydroxylation and whole cell biotransformation: using the unsaturated fatty linoleic acid supplementation with whole cells of $Y$. lipolytica, $1.9 \mathrm{~g} / \mathrm{L} \delta$-decalactone were obtained (Fig. 3). This study represents the first production of $\delta$-decalactone using unsaturated fatty acid as precursor, with the highest yield reported so far.

\section{<Insert figure 3 here>}

Other studies carried out in the last fifteen years on the use of NCYs for producing lactones via biotransformation of fatty acids are reported in Table 2 .

\section{<Insert table 2 here>}

\subsection{Terpenes and terpenoids}

Terpenes are widespread in nature, mainly as constituents of essential oils, and are also obtained in large scale as industrial residues. They are composed of isoprene units, and can be cyclic, openchained, saturated, unsaturated, and oxidized. Monoterpenes represent a valuable resource for the 
flavor industry, and include over 400 different naturally occurring structures constituents of essential oils. Because of low odor activity, high hydrophobicity and their high tendency to autooxidize and polymerize, some monoterpenes are usually separated from oils by rectification. Thus, a few abundant monoterpenes, namely $\alpha$-pinene and limonene, may be considered industrial wastes and inexpensive starting materials for chemical and biochemical transformations. In this framework, the rising consumer demand for natural flavors have determined the development of novel prokaryotic and eukaryotic biocatalysts to biotransform monoterpenes into their more valuable food-grade oxygenated derivatives (van Rensburg 1997, de Carvalho 2006).

$\alpha$-Pinene is a low-price bicycle monoterpene largely employed in flavor industries as raw material for the synthesis of high-value products (Gomes 2001, da Silva 2003), and is commonly used as substrates for biotransformation. Different NCYs, isolated from orange juice industry residues, soils of citric fruits, and leaves of citric fruits, were able to convert the substrate (-)- $\alpha$-pinene to verbenol (Fig. 4) (Rottava 2010).

\section{<Insert figure 4 here>}

The biotransformations of $\alpha$ - and $\beta$-pinene by seven different microorganisms, including whole cells of Candida albicans have been studied (Javidnia 2009). The results showed that this species was unable to biotransform $\alpha$-pinene, while traces of sabinol, myrtenol and myrtenal were observed. $(+)$-Limonene is one of the most studied precursor for the production of food-grade flavors via biotrasformation. Different NCYs were screened to biotransform this molecule to flavoring compounds (van Rensburg 1997): Blastobotrys adeninivorans (former Arxula adeninivorans) and $Y$. lipolytica exhibited a superior ability to convert (+)-limonene to perillic acid by hydroxylation on the exo-cyclic methyl group (Fig. 5). More recently, Ferrara et al. (2013) reported a study on the bioconversion of R-(+)-limonene to perillic acid by whole cells of $Y$. lipolytica. Interestingly, the stepwise addition of limonene increased the perillic acid concentration by over $50 \%$.

\section{<Insert figure 5 here>}

The biotransformation of (-)-(R)- $\alpha$-phellandrene with 16 different microorganisms, including some NCYs, has been recently reported (Iscan 2012): the major product (yields 16\%) obtained by Y. lipolytica-promoted biotransformation was identified as 5-p-menthene-1,2-diol (Fig. 6). 
The microbial and enzymatic biotransformation of some monoterpenoids (i.e. carvone, myrtenal and geraniol) into highly valuable flavoring derivatives is becoming of increasing interest because of their economic potential for the food, and beverage industry (Brenna et al. 2011, Lemos et al. 2009). Carvone is a monoterpenoid isolated from the essential oil of spearmint, and can be synthesized from d-limonene. It can occur in the dextro, levo, and racemic form. d-Carvone exhibits odor reminiscent of caraway, and is used as food-grade flavoring ingredient, exhibiting odor of spearmint. It is usually prepared by fractional distillation of oil caraway or also from dillseed and dillweed oils, but this type differs in odor and flavor. The reduced derivatives of carvones, such as cis-dihydrocarvone and dihydrocarveol also found application as flavoring ingredients. cisDihydrocarvone has a warm, powerful, herb-like odor and a spearmint-like flavor, and may be synthesized by isomerization of limonene oxide, by oxidation of dihydrocarveol or reduction of carvone. Dihydrocarveol has a floral, woody odor and a sweet, somewhat spicy flavor (peppery).

Different NCYs were found to be able to catalyze the reduction of $\mathrm{C}=\mathrm{C}$ and $\mathrm{C}=\mathrm{O}$ double bonds in carvones competitively, affording a mixture of saturated ketones, saturated alcohol and, more rarely, the allylic alcohol. Since 1990s, a number of ascomycetous and basidiomycetous NCYs, belonging to species of the genera Dekkera, Eremothecium, Geotrichum, Hanseniaspora, Kloeckera, Kluyveromyces, Lipomyces, Metschnikowia, Pichia, Rhodotorula, Schwanniomyces, Sporodiobolus, Torulaspora, Trichosporon, and Yarrowia were screened for the their ability to catalyze the biotransformation of monoterpenoid ketones. Although with different enzyme activity, almost all NCYs tested gave reduction of carvone (Fig. 7 and 8). (4R)-carvone was often reduced much faster than $(4 S)$-carvone, and yields of up to $90 \%$ were obtained within a few hours. Some NCYs also exhibited the ability to reduce the $\mathrm{C}=\mathrm{C}$ bond to yield dihydrocarvone isomers with the stereochemistry at $\mathrm{C}-1$ always $R$, while with other yeasts the $\mathrm{C}-\mathrm{O}$ double bond was also reduced to give the dihydrocarveols with stereochemistry at C-2 always $S$ for (4R)-carvone, but sometimes $S$ and sometimes $R$ for (4S)-carvone (van Dyk 1998).

The reduction of $(4 R)$ - or (4S)-carvones catalyzed by Schizosaccharomyces octosporus whole cells showed that the stereochemistry of the ketones determined the reduction pathway reported in Fig. 7 (Carballeira 2004 et al.), where $(4 S)$-carvone yields $(2 R, 4 S)$-carveol (50\% yield) and the $(4 R)$ carvone carries to $(1 R, 2 S, 4 R)$-dihydrocarveol ( $80 \%$ yield) as the major product. In another study, (Goretti et al. 2009) a set of environmental NCYs lyophilized whole cells were screened for their aptitude to reduce $(4 S)$-carvone. Although the species Lindnera amylophila and Kazachstania naganishii (formerly Pichia amylophila and Saccharomyces naganishii, respectively) exhibited a bioconversion of this compound close to $100 \%$, a quite different biocatalytic route was found (Fig. $7)$. In the first case, a mixture of $(1 R, 2 S, 4 S)$ - and $(1 S, 2 S, 4 S)$-dihydrocarveol are produced as the 
major compounds (25.3 and 63\% respectively), by the consecutive reduction of $\mathrm{C}-\mathrm{C}$ and $\mathrm{C}-\mathrm{O}$ double bonds respectively; on the contrary, the cells of L. naganishii catalyzed almost exclusively the reduction of the carbon-carbon double bond of $(4 S)$-carvone affording $(1 S, 4 S)$ - and $(1 R, 4 S)$ dihydrocarvones (44.4 and $39.7 \%$ respectively) as major products.

\section{<Insert figure 7 here>}

The prevalent catalytic activity was the ene-reductase(ER)-catalyzed reduction of the substrate into a mixture of $(1 R, 4 R)$ - and $(1 S, 4 R)$-dihydrocarvone, with a clear-cut preference towards the production of $(1 R, 4 R)$-diastereomer. Variable amounts of dihydrocarveols, derived from the subsequent carbonyl reductase-catalyzed reduction of the carbonyl group were sometimes produced. Hanseniaspora guilliermondii exhibited a good bioconversion yield (about 63\%), coupled with an excellent selectivity (diastereomeric excess, d.e. $=98 \%$ ), compatible with its application as potential source of dihydrocarvone (Goretti et al. 2009). Response surface methodology was also recently applied for simultaneously maximize the bioreduction yield of $(4 S)$ (+)-carvone (>95\%) by whole cells of Cryptococcus gastricus and to minimize the rate of side reactions below 1\% (Goretti et al. 2012). Bioreduction of (4R)-carvone promoted by NCYs whole cells of the genera Candida, Cryptococcus, Debaryomyces, Hanseniaspora, Kazachstania, Kluyveromyces, Lindnera, Nakaseomyces, Vanderwaltozyma and Wickerhamomyces has also been reported [Goretti et al. 2013]. The ene-reductase (ER)-catalyzed reduction of the substrate into a mixture of $(1 \mathrm{R}, 4 \mathrm{R})$ - and $(1 \mathrm{~S}, 4 \mathrm{R})$-dihydrocarvone was showed to be the prevalent catalytic activity, with a clear-cut preference towards the production of $(1 R, 4 R)$-diastereomer. The dihydrocarveols, derived from the subsequent carbonyl reductase-catalyzed reduction of the carbonyl group, were found only in traces. Hanseniaspora guilliermondii exhibited a good bioconversion yield (about $63 \%$ ), coupled with an excellent selectivity (diastereomeric excess, d.e. $=98 \%$ ), compatible with its application as potential source of dihydrocarvone.

Goretti et al. (2011) recently reported. the biotransformation of some terpene aldehydes [(S)perillaldehyde and the aromatic terpene aldehyde $\alpha$-methyl-cinnamaldehyde] by a set of NCYs. NCYs reduce the monocyclic $(S)$-perillaldehyde with moderate yields: whole cells of $K$. naganishii gave bioconversion yields higher than 60\% (Fig. 8). (S)-Perillaldehyde was initially reduced to dihydro-perillaldehyde and successively to dihydroperillic alcohol. Furthermore, it is noteworthy that the same species catalyzed the direct reduction of the carbonyl group of $(S)$-perillaldehyde, which led to the formation of perillic alcohol. 


\section{<Insert figure 8 here>}

On the contrary, NCYs poorly reduced $\alpha$-methyl-cinnamaldehyde: only Kazachstania spencerorum exhibited bioconversion yields higher than $60 \%$. $\alpha$-Methyl-cinnamaldehyde was initially reduced to $\alpha$-methyl-dihydro-cinnamaldehyde, while the subsequent reduction of the carbonyl group led to the formation of $\alpha$-methyldihydrocinnamyl alcohol (Fig. 9).

\section{<Insert figure 9 here>}

The biotransformation of the $\alpha, \beta$-unsaturated aldehyde $(1 R)$-myrtenal catalyzed by NCYs was also investigated (Goretti et al. 2013). Overall, NCYs showed good (sometimes even excellent) aptitudes to biotransform (1R)-myrtenal into derivative compounds (Fig. 10): about one third of strains gave percentage of conversion $\geq 95 \%$. Among them, Candida freyschussii and K. spencerorum converted $100 \%$ of the precursor. Interestingly, in almost all cases, biocatalytic ability was prevalently driven towards the reduction of $\mathrm{C}=\mathrm{O}$ catalysed by carbonyl reductases (CRs) associated to whole cells, affording myrtenol as the main product of the bioconversions. On the contrary, the results obtained apparently suggest that (1R)-myrtenal is not a good substrate for the ER activity.

\section{$<$ Insert figure 10 here>}

The ability of NCYs to convert acyclic monoterpenes (e.g., geraniol and nerol) has received little attention. NCYs can produce linalool and $\alpha$-terpineol from both geraniol and nerol (King and Dickinson 2000). Torulaspora delbrueckii also exhibited the ability to form geraniol from nerol (King and Dickinson 2000). More recently, a set of NCYs have been screened for their ability to biotransform the acyclic monoterpenes geraniol and nerol (Fig. 11) (Ponzoni et al. 2008). The aptitude to convert both compounds was apparently frequent in NCYs. The production of linalool, $\alpha$-terpineol, $\beta$-myrcene, d-limonene, (E)- $\beta$-ocimene, (Z)- $\beta$-ocimene, or carene was observed, depending upon the substrate used: thus, linalool was the main product obtained from geraniol, whereas linalool and $\alpha$-terpineol were the main products obtained through the conversion of nerol. Yet, differently from nerol, the aptitude to exhibit high bioconversion yields of geraniol to linalool was an apparently genus-related character, whereas the ability to produce other monoterpenes was a both genus- and habitat-related character (Ponzoni et al. 2008).

\section{<Insert figure 11 here>}


The reduction of $\mathrm{C}-\mathrm{C}$ double bonds represents a powerful tool in asymmetric synthesis, and different methods to accomplish this reaction are available on industrial scale (Winkler et al. 2012). Bioreduction of carbonyl-activated alkenes to flavoring food-grade compounds has been reported. The ability of NCYs to bioreduce the $\alpha, \beta$-unsaturated ketones ketoisophorone, 2-methyl- and 3methyl-cyclopentenone has been checked by Goretti et al. (2011). Generally, NCYs exhibited an extremely high capability (currently 90 or even $100 \%$ yields) to reduce, via ER activity, the conjugated $\mathrm{C}=\mathrm{C}$ bond of ketoisophorone and 2-methyl-ciclopentenone (Fig. 12).

\section{<Insert figure 12 here >}

Due to low competing CRs activities, high chemoselectivity was sometimes observed, together with a moderate stereoselectivity for $R$-isomers: an enantiomeric excess varying from 10 to $44 \%$ was found for $6 R$-dihydro-oxoisophorone, 6R-DOIP, (Fig. 12). 6R-DOIP is a key food-grade aroma constituent of tobacco and saffron (Sode et al. 1987), and, interestingly, K. spencerorum converted more than $80 \%$ of KIP in $6 R$-DOIP, which represented, after $24 \mathrm{~h}$., the almost exclusive product of bioreduction.

NCYs whole cells also showed a moderate ability to bioreduce 2-methyl-cyclopentenone (2MCPO): whole cells of Debaryomyces coudertii, Debaryomyces nepalensis and K. spencerorum exhibited bioconversion yields higher than $90 \%$ following the scheme reported in Fig. 13.

\section{<Insert figure 13 here>}

\subsection{Sulphur compounds}

A number of sulphur compounds such as methanethiol, dimethyl disulphide, dimethyl trisulphide, S-methylthioacetate and S-methylthiobutyrate have been identified as normal components of aroma of cheeses and truffles (Molimard and Spinnler 1996; López del Castillo-Lozano et al., 2007). Bondar et al. (2005) early reported the biotrasformation of L-methionine to 4-methylthio-2oxobutyric acid, via transamination catalyzed by $Y$. lipolytica.

In recent years, some studies explored the ability of NCYs to biotransform L-methionine into a set of volatile sulphur compounds (VSC). A set of strains belonging to both Ascomycota (genera Candida, Debaryomyces, Geotrichum, Kluyveromyces, Lindnera and Yarrowia) and Basidiomycota (Cryptococcus, Rhodotorula and Trichosporon) exhibited the aptitude to biotransform L-methionine or L-methionine/L-cysteine mixtures into 2-methyl butanol, 3-methyl 
butanol, methanethiol, S-methyl thioacetate, dimethyl sulfide, dimethyl disulfide, dimethyl trisulfide, dihydro-2-methyl-3(2H)-thiophenone, 3-(methylthio)-1-propene, 3-(methylthio)-1propanal, 3-(methylthio)-1-propanol, 3-(methylthio)-1-propyl acetate, 3-(methylthio)-1-propanoic acid and ethyl 3-(methylthio)-1-propanoate (Buzzini et al. 2005, López del Castillo-Lozano et al. 2007, Tan et al. 2012, Koh et al. 2013).

3-(Methylthio)-1-propanol (methionol), which has cauliflower- and cabbage-like aroma, is of great importance in the overall aroma of soy sauce and cheese (Yvon and Rijnen 2001). Different yeasts (Candida kefyr, Candida utilis, Kluyveromyces lactis, Saccharomyces bayanus, Saccharomyces chevalieri, Candida famata (previously Torulopsis candida) and Williopsis saturnus were recently screened for their ability to produce flavour-active methionol in coconut cream supplemented with L-methionine (Seow et el. 2010). The yeasts showed different ability to produce methionol from methionine (Fig. 14), with Kluyveromyces lactis producing the most. More recently, the bioproduction of methionol from $K$. lactis was optimized be the application of response surface methodology (RSM) and fractional factorial design methods: under the optimum conditions the production of methionol reached $990.1 \pm 49.7 \mu \mathrm{g} / \mathrm{mL}$ (Koh et al. 2013).

\section{<Insert figure 14 here>}

Tan et al. (2010) reported the first study on the production of VSCs in relation to L-methionine catabolism by yeasts from the genus of Williopsis. Five strains were screened for VSC production in a synthetic medium supplemented with L-methionine. A diverse range of VSCs were produced, including methional, methionic acid, 3-(methylthio)propyl acetate, and 3-(methylthio)propionic acid ethyl ester.

An investigation on how VSC production by yeasts could be affected through the supplementation of methionine-cysteine mixtures in comparison with methionine alone has been reported (López del Castillo-Lozano et al. 2007). In this study four cheese-ripening NCYs yeasts were screened, i.e. Debaryomyces hansenii, Kluyveromyces lactis, Geotrichum candidum, and Yarrowia lipolytica: all of them produced VSC with L-methionine or L-methionine/L-cysteine, although with different VSC profiles, confirming the hypothesis of the authors that L-methionine must be present in culture medium for the production of VSC by the yeast. Furthermore, this study showed that L-methionine is catabolized to a lower extent when L-cysteine is also added in the cultures.

\subsection{Phenols}


The ability of yeasts to utilize monomeric phenolic compounds is a well-know phenomenon (Middelhoven 1992). Here, a typical example is the biosynthesis of vanillin. This compound (4hydroxy-3-methoxy-benzaldehyde) is the second highest produced aroma component in the world (Zheng et al. 2007) and plays an important role in foods and beverages, as well as in other industries (Priefert et al. 2001). It is usually produced via extraction from vanilla beans (natural vanillin content $2 \%$ ) or via chemical synthesis from guaiacol and lignin, leading to a cheaper product but of lower quality (Clark 1990).

Like to other flavoring compounds, the trends towards natural flavors and the high price of natural vanillin has driven the search of microbial processes as alternative sources of natural vanillin via biocatalytic transformation of ferulic acid. Though the biotransformation of this precursor to vanillin has been extensively studied (Priefert 2001), there are other value-added minor metabolites produced during this biodegradation, including 4-vinyl guaiacol, vanillic acid, acetovanillone, vanillyl alcohol, dihydroferulic acid, coniferyl alcohol, dihydroconiferyl alcohol or homovanillic acid (Shanker 2007). However, only few studies regarding production of vanillin and associated metabolites by yeast strains are reported.

Whole cells of $D$. hansenii metabolized ferulic acid to 4-vinyl guaiacol by the non-oxidative decarboxylation of its side chain (Mathew 2007). This biotransformation is a highly value added process as 4-vinyl guaiacol is nearly 40 times costlier than ferulic acid. Whole cells of $D$. hansenii produced $1470 \mathrm{mg} / \mathrm{L}$ of vinyl guaiacol in ten hour, corresponding to a molar yield of $95 \%$. However, the production of vanillin from 4-vinyl guaiacol through this biotechnological route is considered not very economical as the vanillin levels were $169 \mathrm{mg} / \mathrm{L}$ at the fifth hour.

Recently Max et al. [2012] used a factorial design to optimize the biotransformation of ferulic acid into higher value added products such as 4-vinyl guaiacol, vanillic acid and acetovanillone by whole cells of $D$. hansenii (Fig. 15). The major degradation products of ferulic acid were 4-vinyl guaiacol after $72 \mathrm{~h}$ (molar yield of $86.0 \%$ ), vanillic acid after $360 \mathrm{~h}$ (molar yield of $91.1 \%$ ) or acetovanillone after $408 \mathrm{~h}$ (molar yield of 98.8\%). Traces of vanillin, vanillyl alcohol or 4ethylguaiacol were also found. Previous studies have also reported that Rhodotorula mucilaginosa (former Rhodotorula rubra), Rhodotorula minuta and Pichia fermentans (former Candida lambica) (Donaghy 1999) were able to transform ferulic acid into 4-vinylguaiacol.

\section{<Insert figure 15 here>}

A recent study showed the evidence for biotransformation of isoeugenol to vanillin and vanillic acid by a strain of Candida galli (Ashengroph et al. 2011). This yeast strain, isolated from oil- 
contaminated water, was able to transform isoeugenol to vanillin and vanillic acid, yielding a vanillin concentration of $1.12 \mathrm{gl}^{-1}$ (Fig. 16)

\section{<Insert figure 16 here>}

\section{Conclusions}

Flavors are key players for modifying and improving organoleptic quality of a number of foods and beverages. There is a general trend pushing towards the progressive replacement of flavoring additives produced via chemical synthesis with those obtained from natural sources, including plants, food-grade microorganisms and enzymes in order to meet the rising consumer requests for natural flavors and fragrances.

In this way, the use of microbial whole cells for catalyzing alternative and attractive routes for the production of these compounds via biotransformation have been extensively studied. However, despite the high number of studies so far published, only a few processes have been successfully scaled-up to the industrial scale, while most of other possible biotransformations are still confined to the laboratory scale.

NCYs whole cells could be considered as excellent biocatalysts for promoting and scaling-up cheap system for producing food-grade flavors. The array of flavors potentially produced by whole cells of NCYs via biotransformation of suitable precursors may match with ever increasing biological and metabolic diversity these organisms. So, the study of NCYs, together with the interaction among yeast biodiversity, synthetic biology, DNA recombinant technology and yeast biotechnology may improve in the future the biological (e.g. bioactivity, olfactory properties, etc.) and the physico-chemical properties (e.g. solubility, lipophilic aptitude, etc.) of flavors, available in the market (Antoniotti et al. 2014).

\section{References}

Aguedo, M., Ly, M.H., Belo, I., Teixeira, J.A., Belin, J.M., Waché, Y, 2004.The use of enzymes and microorganisms for the production of aroma compounds from lipids. Food Technol. Biotechnol. 42, 327-336.

An, J.-U.; Joo, Y.-C., Oh D.-K., 2013. New biotransformation process for production of the fragrant compound $\gamma$-dodecalactone from 10-hydroxystearate by permeabilized Waltomyces lipofer cells. Appl. Environ. Microbiol. 79, 2636-2641. 
Andreu, C., del Olmo, M., 2014. Potential of some yeast strains in the stereoselective synthesis of (R)-(-)-phenylacetylcarbinol and (S)-(+)-phenylacetylcarbinol and their reduced 1,2-dialcohol derivatives. Appl. Microbiol. Biotechnol. 98, 5901-5913.

Antoniotti, S., 2014. Tuning of essential oil properties by enzymatic treatment: toward sustainable processes for the generation of new fragrance ingredients. Molecules. 19, 9203-9214.

Armstrong, D. W., Martin, S. M., Yamazaki, H., 1984. Production of acetaldehyde from ethanol by Candida utilis. Biotechnology Letters. 6(3), 183-188.

Ashengroph, M., Nahvi, I., Zarkesh-Esfahani, H., Momenbeik, F., 2011. Candida galli strain PGO6: a novel isolated yeast strain capable transformation of isoeugenol into vanillin and vanillic acid. Curr. Microbiol. 62, 990-998.

Bastos Borges, K., de Souza Borges, W., Durán-Patrón, R., Tallarico Pupo, M., Sueli Bonato, P., González Collado, I., 2009. Stereoselective biotransformations using fungi as biocatalysts. Tetrahedron Asymmetry. 20, 385-397.

Bondar, D.C., Beckerich, J.M., Bonnarme, P. 2005. Involvement of a branched-chain aminotransferase in production of volatile sulfur compounds in Yarrowia lipolytica. Appl. Environ. Microbiol. 71(8), 4585-4591.

Bourel, G., Nicaud, J.M., Nthangeni, B., Santiago-Gomez, P., Marc Belin, J., Husson, F., 2004. Fatty acid hydroperoxide lyase of green bell pepper: cloning in Yarrowia lipolytica and biogenesis of volatile aldehydes. Enzyme Microb. Technol. 35, 293-299.

Braga, A., Belo, I., 2015. Production of $\gamma$-decalactone by Yarrowia lipolytica: insights into experimental conditions and operating mode optimization. Chem. Technol. Biotechnol. 90, 559565.

Brenna, E., Fuganti, C., Gatti, F.G., Serra, S., 2011. Biocatalytic Methods for the Synthesis of Enantioenriched Odor Active Compounds. Cemical Reviews. 111, 4036-4072.

Buchhaupt, M., Guder, J.C., Etschmann, M.M., Schrader, J., 2012. Synthesis of green note aroma compounds by biotransformation of fatty acids using yeast cells coexpressing lipoxygenase and hydroperoxide lyase. Appl. Microbiol. Biotechnol. 93, 159-168.

Buzzini, P., Gasparetti, C., Turchetti, B., Cramarossa, M.R., Vaughan-Martini, A., Martini, A., Pagnoni, U.M., Forti L., 2005. Production of volatile organic compounds (VOCs) by yeasts isolated 
from the ascocarps of black (Tuber melanosporum Vitt.) and white (Tuber magnatum Pico) truffle. Arch. Microbiol. 184, 187-193.

Buzzini, P., Vaughan-Martini, A., 2006. Yeast biodiversity and biotechnology, in: Rosa, C.A., Peter, G. (Eds.), Biodiversity and ecophysiology of yeasts. Springer, Berlin, pp. 533-559.

Carballeira, J.D., Valmaseda, M., Alvarez, E., Sinisterra Gago J.V. 2004. Gongronella butleri, Schizosaccharomyces octosporus and Diplogelasinospora grovesii: novel microorganisms useful for the stereoselective reduction of ketones. Enz. Microb. Technol., 34, 611-623.

Clark, G.S., 1990. Vanillin. Perfum Flavor 15,45-54.

Dahlen, T., Hauck, T., Wein, M., Schwab, W., 2001. 2,5-dimethyl-4-hydroxy-3(2H)-furanone as a secondary metabolite from D-fructose-1,6-diphosphate metabolism by Zygosaccharomyces rouxii. J. Biosci. Bioeng. 91, 352-358.

da Silva, M.J., Robles-Deutenhefner, P.; Menini, L.; Gusevskaya, E.V., 2003. Cobalt catalyzed autoxidation of monoterpenes in acetic acid and acetonitrile solutions. J. Mol. Catal. A: Chemical, 201, 71-77.

de Carvalho, C. C. R., da Fonseca, M. M. R., 2006. Biotransformation of terpenes. Biotechnol. Adv. 24, 134-142, and refs. cit. herein.

de Carvalho, C.C., 2011. Enzymatic and whole cell catalysis: finding new strategies for old processes. Biotechnol. Adv., 29, 75-83.

Demyttenaere, J. C. R., 2012. The new European Union Flavouring Regulation and its impact on essential oils: production of natural flavouring ingredients and maximum levels of restricted substances. Flavour Frag. J., 27, 3-12.

Donaghy, J.A., Kelly, P.F., McKay, A., 1999. Conversion of ferulic acid to 4-vinyl guaiacol by yeasts isolated from unpasteurised apple juice. Sci. Food Agric. 79, 453-456.

Domínguez, Á., Fermiñán, E., Sánchez, M., González, F.J., Pérez-Campo, F.M., García, S., Herrero, A.B., San Vicente, A., Cabello, J., Prado, M., Iglesias, F.J., Choupina, A., Burguillo, F.J., Fernández-Lago, L., López, M.C. 1998. Non-conventional yeasts as hosts for heterologous protein production. Internatl. Microbiol. 1, 131-142. 
Dufossé, L., Feron, G., Mauvais, G., Bonnarme, P., Durand, A., Spinnler, H.-E., 1998. Production of $\gamma$-Decalactone and 4-Hydroxy-Decanoic Acid in the Genus Sporidiobolus. J. Ferment. Bioeng. 86, 169-173.

Elss, S., Preston, C., Hertzig, C., Heckel, F., Richling, E., Schreier, P., 2005. Aroma profiles of pineapple fruit (Ananas comosus [L.] Merr.) and pineapple products. LWT Food Sci. Technol., 38, 263-274.

Escamilla-Garcia, E., Aguedo, M., Gomes, N., Choquet, A., Belo, I., Teixeira, J.A., Belin, J.-M., Waché, Y., 2009. Production of 3-hydroxy- $\gamma$-decalactone, the precursor of two decenolides with flavouring properties, by the yeast Yarrowia lipolytica. J. Mol. Catal. B: Enzymatic. 57, 22-26.

Escamilla-Garcia, E., Belin, J.-M., Waché, Y., 2007. Use of a Doehlert factorial design to investigate the effects of $\mathrm{pH}$ and aeration on the accumulation of lactones by Yarrowia lipolytica. J. Appl. Microbiol. 103, 1508-1515.

Etschmann, M.M.W.; Schrader, J., 2006. An aqueous-organic two-phase bioprocess for efficient production of the natural aroma chemicals 2-phenylethanol and 2-phenylethylacetate with yeast. Appl. Microbiol. Biotechnol. 71, 440-443.

Etschmann, M.M.W.; Sell, D.; Schrader, J., 2004, Medium optimization for the production of the aroma compound 2-phenylethanol using a genetic algorithm. J. Mol. Catal. B: Enzymatic. 29, 187193.

Etschmann, M.M.W., Sell, D., Schrader, J., 2005. Production of 2-Phenylethanol and 2Phenylethylacetate from L-Phenylalanine by Coupling Whole-Cell Biocatalysis with Organophilic Pervaporation. Biotechnol. Bioeng. 92, 624-634.

Faber, K., 2004. Biotransformations in Organic Chemistry, 5th ed. Springer-Verlag: Berlin/Heidelberg, Germany. pp. 3-11.

Fabre, C.E., Blanc, P.J., Goma, G., 1998. Production of 2-phenylethyl alcohol by Kluyveromyces marxianus. Biotechnol. Progr. 14, 270-274.

Farbood, M.I., Morris, J.A., McLean, L.B., 1998. Fermentation process for preparing 10-hydroxyC18-carboxylic acid and gamma-dodecalactone derivatives. European patent 0578388. 
Fauconnier, M.L., Mpambara, A., Delcarte, J., Jacques, P., Thonart, P., Marlier, M., 1999. Conversion of green note aldehydes into alcohols by yeast alcohol dehydrogenase. Biotechnol. Lett. 21, 629-633.

Feron, G., Waché, Y., 2005. Microbial biotechnology of food flavor production, in: Dominick, T. (Ed.), Food biotechnology, 2nd ed., Dekker, New York, pp 407-441.

Ferrara, M. A., Almeida, D.S., Siani, A.C., Lucchetti, L., Lacerda, P.S.B., Freitas, A., Tappin, M.R.R., Bon, E.P.S., 2013. Bioconversion of R-(+)-limonene to perillic acid by the yeast Yarrowia lipolytica. Brazilian J. Microbiol. 44(4), 1075-1080.

Flores, C.L., Rodriguez, C., Petit, T., Gancedo, C., 2000. Carbohydrate and energy-yielding metabolism in non-conventional yeasts. FEMS Microbiol. Rev. 24, 507-529.

Gao, F., Daugulis A.J., 2009. Bioproduction of the Aroma Compound 2-Phenylethanol in a SolidLiquid Two-Phase Partitioning Bioreactor System by Kluyveromyces marxianus. Biotechnol. Bioeng. 104, 332-339.

Garavaglia, J., Flôres, S.H., Pizzolato, T.M., Peralba, M.C., Ayub, M.A.Z., 2007. Bioconversion of L-phenylalanine into 2-phenylethanol by Kluyveromyces marxianus in grape must cultures. World J. Microbiol. Biotechnol. 23, 1273-1279.

Gigot, C., Ongena, M., Fauconnier, M.-L., Muhovski, Y., Wathelet, J.-P., du Jardin, P. , Thonart, P., 2012. Optimization and scaling up of a biotechnological synthesis of natural green leaf volatiles, using Beta vulgaris hydroperoxide lyase. Process Biochem. 47, 2547-2551.

Gomes, M. Jr., Antunes, O.A.C., 2001. Upjohn Catalytic Osmium Tetroxide Oxidation Process: Diastereoselective Dihydroxylation of Monoterpenes. Catal. Commun. 2, 225-227.

Goretti, M., Ponzoni, C., Caselli, E., Marchegiani, E., Cramarossa, M.R., Turchetti, B., Buzzini, P., Forti, L., 2009. Biotransformation of electron-poor alkenes by yeasts: asymmetric reduction of (4S)(+)-carvone by yeast enoate reductases. Enzyme Microb. Technol. 45, 463-468.

Goretti M., Ponzoni, C., Caselli, E., Marchegiani, E., Cramarossa, M.R., Turchetti, B., Forti, L., Buzzini, P., 2011. Bioreduction of $\alpha, \beta$-unsaturated ketones and aldehydes by non-conventional yeast (NCY) whole-cells. Bioresour. Technol. 102, 3993-3998.

Goretti, M., Ponzoni, C., Caselli, E., Marchigiani, E., Cramarossa, M.R., Turchetti, B., Buzzini, P., 
Goretti, M.. Branda, E., Turchetti, B., Cramarossa, M.R., Onofri, A., Forti, L., Buzzini, P. 2012. Response surface methodology as optimization strategy for asymmetric bioreduction of (4S)-(+)carvone by Cryptococcus gastricus. Biores. Technol. 121, 290-297.

Goretti, M., Turchetti, B., Cramarossa, M.R., Forti, L., Buzzini, P., 2013. Production of flavours and fragrances via bioreduction of (4R)-(-)-carvone and (1R)-(-)-myrtenal by non-conventional yeast whole-cells. Molecules, 18, 5736-5748.

Groguenin, A., Waché, Y., Escamilla-Garcia, E., Aguedo, M., Husson, F., LeDall, M.-T., Nicaud, J.-M., Belin, J.-M., 2004. Genetic engineering of the $\beta$-oxidation pathway in the yeast Yarrowia lipolytica to increase the production of aroma compounds. J. Mol. Catal. B: Enzymatic. 28, 75-79.

Herianus, J.D.L., Zora, S., Soon, C.T., 2003. Aroma volatiles production during fruit ripening of 'Kensington Pride' mango. Postharvest Biol. Technol. 27, 323-336.

Hua, D., Xu, P., 2011. Recent advances in biotechnological production of 2-phenylethanol. Biotechnol. Adv., 29, 654-660.

Huang, C.J., Lee, S.L., Chou, C.C., 2000. Production and molar yield of 2-phenylethanol by Pichia fermentans L-5 as affected by some medium components. J. Biosci. Bioeng. 90, 142-147.

Huang, C.J., Lee, S.L., Chou, C.C., 2001. Production of 2-phenylethanol, a flavor ingredient, by Pichia fermentans L-5 under various culture conditions. Food Res. Int. 34, 277-282.

Işcan, G., Kırımer, N., Demirci, F., Demirci, B., Noma, Y., Başer, K.H.C., 2012. Biotransformation of (-)-(R)- $\alpha$-Phellandrene: Antimicrobial Activity of Its Major Metabolite. Chem. Biodivers. 9, 1525-1532.

Ishida, T., 2005. Biotransformation of terpenoids by mammals, microorganisms, and plant-cultured cells. Chem. Biodivers. 2, 569-590.

Janssens, L., de Pooter, H.L., Vandamme, E.J., Schamp, N.M., 1992. Production of flavours by microorganisms. Process Biochem. 195-215.

Javidnia, K., Aram, F., Solouki, M., Reza Mehdiopour, A., Gholami, M., Miri, R., 2009. Microbial biotransformation of some monoterpene hydrocarbons. Ann. Microbiol. 59, 349-351. 
Johnson, E.A., Echavarri-Erasun, C. 2011.Yeast biotechnology, in: Kurtzman, C.P., Fell, J.W., Boekhout, T. (Eds.), The Yeasts, a Taxonomic Study, 5th ed.,vol. 1. Elsevier, Amsterdam, pp. 2144.

Kang, W.-R., Seo, M.-J., An, J.-U., Shin, K.C, Oh, D,-K., 2016. Production of d-decalactone from linoleic acid via 13-hydroxy-9(Z)-octadecenoic acid intermediate by one-pot reaction using linoleate 13-hydratase and whole Yarrowia lipolytica cells. Biotechnol. Lett. 38(5), 817-23.

Karagül-Yüceer, Y., Drake, M.A., Cadwallader, K.R., 2001. Aroma-active components of non-fat dry milk. J. Agric. Food Chem. 49, 2948-2953.

King, A., Dickinson, J.R., 2000. Biotransformation of monoterpene alcohols by Saccharomyces cerevisiae, Torulaspora delbrueckii and Kluyveromyces lactis. Yeast, 16, 499-506.

Koh M.K.P., Sun J., Liu S.-Q., 2013. Optimization of L-methionine bioconversion to aroma-active methionol by Kluyveromyces lactis using the Taguchi method. J. Food Res. 2(4), 90-100.

Kondo, A., Liu, Y., Furuta, M., Fujita, Y., Matsumoto, T., Fukuda, H., 2000, Preparation of high activity whole cell biocatalyst by permeabilization of recombinant flocculent yeast with alcohol. Enzyme Microb. Technol. 27, 806-811.

Krings, U., Berger, R.G., 1998. Biotechnological production of flavours and fragrances. Appl. Microbiol. Biotechnol. 49(1), 1-8.

Kurtzman, C.P., Fell, J.W., Boekhout, T. (Eds.), 2011. The yeasts, a taxonomic study. Elsevier: Amsterdam.

Lee, Y.J., Kim, C.S., Oh, D.K., 2004, Lactulose production by betagalactosidase in permeabilized cells of Kluyveromyces lactis. Appl. Microbiol. Biotechnol. 64, 787-793.

Lemos, B.J., Dionsio, A.P., Pastore, G.M., 2009. Bio-oxidation of terpenes: An approach for the flavor industry. Chem. Rev. 109, 4518-4531.

Liese, A., Seelbach, K., Wandrey, C. (Eds.), 2006. Industrial Biotransformations, 2nd ed.; WileyVCH: Weinheim, Germany.

Lomascolo, A., Stentelaire, C., Aster, M., Lesage-Meessen, L., 1999. Basidiomycetes as new biotechnological tools to generate natural aromatic flavours for the food industry. Trends Biotechnol. 17, 282-289. 
Longo, M.A., Sanroman, M.A., 2006. Production of food aroma compounds. Food Technolol. Biotechnol. 44(3), 335-353.

López del Castillo-Lozano, M., Delile, A., Spinnler, H.E., Bonnarme, P., Landaud, S., 2007. Comparison of volatile sulphur compound production by cheese-ripening yeasts from methionine and methionine-cysteine misture. Appl. Microbiol. Biotechnol. 75, 1447-1454.

Mathew, S., Abraham, T.E., Sudheesh S., 2007. Rapid conversion of ferulic acid to 4-vinyl guaiacol and vanillin metabolites by Debaryomyces hansenii. J. Mol. Catal. B: Enzymatic. 44, 48-52.

Matsuda, T., Yamanaka, R., Nakamura, K., 2009. Recent progress in biocatalysis for asymmetric oxidation and reduction. Tetrahedron Asymmetry. 20, 513-557.

Max, B., Tugores, F., Cortés-Diéguez, S., Domínguez, J.M., 2012. Bioprocess design for the microbial production of natural phenolic compounds by Debaryomyces hansenii. Appl Biochem. Biotechnol. 168, 2268-2284.

Middelhoven, W.J., Koorevaar, M., Schuur, G., 1992. Degradation of benzene compounds by yeasts in acidic soils. Plant \& Soil. 145, 37-43.

Molimard, P., Spinnler, H.E., 1996. Compounds involved in the flavour of surface mold-ripened cheeses: origins and properties. J. Dairy Sci. 79,169-184.

Moore, J.C., Pollard, D.J., Kosjek, B., Devine P.N., 2007. Advances in the Enzymatic Reduction of Ketones. Acc. Chem. Res. 40, 1412-1419.

Nicaud, J-M., Madzak, C., Van den Broek, P., Gysler, C., Duboc, P., Niederberger, P., Gaillardin, C., 2002. Protein expression and secretion in the yeast Yarrowia lipolytica. FEMS Yeast Res. 2, 371-379.

Nunes, C., Coimbra, M.A., Saraiva, J., Rocha, S.M., 2008. Study of the volatile components of a candied plum and estimation of their contribution to the aroma. Food Chem. 111, 897-905.

Patel, R.N., 2011. Biocatalysis: Synthesis of key intermediates for development of pharmaceuticals. ACS Catal. 1, 1056-1074.

Pino, J.A., Marbot, R., 2001. Volatile flavor constituents of acerola (Malpighia emarginata DC.) fruit. J. Agric. Food Chem. 49, 5880-5882. 
Ponzoni, C., Gasparetti, C., Goretti, M., Turchetti, B., Cramarossa, M.R., Pagnoni, U.M., Forti, L., Buzzini P., 2008. Biotransformation of acyclic monoterpenoids by Debaryomyces sp., Kluyveromyces sp. and Pichia sp. strains of environmental origin. Chem. Biodiv. 5, 471-483.

Priefert, H., Rabenhorst, J., Steinbüchel, A., 2001. Biotechnological production of vanillin. Appl. Microbiol. Biotechnol. 56, 296-314.

Romero-Guido, C., Belo, I., Ta, T.M.N., Cao-Hoang, L., Alchihab, M., Gomes, N., Thonart, P., Teixeira, J.A., Destain, J., Waché, Y., 2011. Biochemistry of lactone formation in yeast and fungi and its utilisation for the production of flavour and fragrance compounds. Appl. Microbiol. Biotechnol., 89, 535-547.

Rottava, I., Cortina, P.F., Zanella, C.A., Cansian, R.L., Toniazzo, G., Treichel, H., Antunes, O.A.C., Oestreicher, E.G., de Oliveira, D., 2010. Microbial oxidation of (-)- $\alpha$-pinene to verbenol production by newly isolated strains. Appl Biochem. Biotechnol., 162, 2221-2231.

Seow, Y.X., Ong, P.K. C., Liu, S.Q., 2010. Production of flavour-active methionol from methionine metabolism by yeasts in coconut cream. International Journal of Food Microbiology, 143(3), 235240.

Shanker, K.S., Kishore, K.H., Kanjilal, S., Misra, S., Murty, U.S.N., Prasad, R.B.N., 2007. Biotransformation of ferulic acid to acetovanillone using Rhizopus oryzae. Biocatal. Biotransfor. 25, 109-112.

Sibirny, A.A., Scheffers, L., 2002. Thematic section 'Biochemistry, Genetics, Biotechnology and Ecology of Non-conventional Yeasts'. FEMS Yeast Res. 2, 293.

Sode, K., Kajiwara, K., Tamiya, E., Karube, I., 1987. Continuous asymmetric reduction of 4oxoisophorone by thermophilic bacteria using a hollow fiber reactor. Biocatal. 1, 77-86.

Spencer, J.F.T., Ragout de Spencer, A.L., Laluce, C., 2002. Non-conventional yeasts. Appl. Microbiol. Biotechnol. 58, 147-156.

Steensels, J., Snoek, T., Meersman, E., Picca Nicolino, M., Voordeckers, K., Verstrepen, K.J., 2014. Improving industrial yeast strains: exploiting natural and artificial diversity. FEMS Microbiol. Rev. 38, 947-995.

Straathof, A.J.J., Panke, S., Schmid, A. 2002. The production of fine chemicals by biotransformations. Curr. Opin. Biotechnol. 13, 548-556. 
Tan, A.W.J., Lee, P.-R., Seow, Y.-X., Ong, P.K.C., Liu, S.-Q., 2012. Volatile sulphur compounds and pathways of L-methionine catabolism in Williopsis yeasts. Appl. Microbiol. Biotechnol. 95,1011-1020.

Vandamme, E.J., Soetaert, W., 2002. Bioflavours and fragrances via fermentation and biocatalysis. J. Chem. Technol. Biotechnol. 77, 1323-1332.

van Dyk, M.S., van Rensburg, E., Rensburg, I.P.B., Moleleki, N. 1998. Biotransformation of monoterpenoid ketones by yeasts and yeast-like fungi. J. Mol. Catal. B Enzymatic. 5, 149-154.

van Rensburg, E., Moleleki, N., van der Walt, J.P., Botes, P.J., van Dyk, M.S. 1997. Biotransformation of (+)-limonene and (-)-piperitone by yeasts and yeast-like fungi. Biotechnol. Lett. 19, 779-782.

Waché, Y., Aguedo, M., Choquet, A., Gatfield, I., Nicaud, J.-M., Belin, J.-M., 2001. Role of $\beta$ oxidation enzymes in the production of $\gamma$-decalactones from methyl ricinoleate. Appl. Environ. Microbiol. 67, 5700-5704.

Waché, Y., Aguedo, M., Nicaud J.-M., Belin, J.-M., 2003. Catabolism of hydroxyacids and production of lactones by the yeast Yarrowia lipolytica. Appl. Microbiol. Biotechnol. 61, 393-404.

Walker, G.M., 1998. Yeast Physiology and Biotechnology, John Wiley and Sons Ltd., Chichester, England.

Winkler, C.K., Tasnádia, G., Clay, D., Hall, M., Faber K., 2012. Asymmetric bioreduction of activated alkenes to industrially relevant optically active compounds. J. Biotechnol. 162, 381-389

Wolf, K., Breunig, K., Barth, G., 2003. Non conventional yeasts in genetics, biochemistry and biotechnology, Springer: Berlin. 79, 453-456

Yvon, M., Rijnen, L., 2001. Cheese flavour formation by amino acid catabolism. International Dairy Journal, 11(4), 185-201.

Zheng, L., Zheng, P., Sun, Z., Bai, Y., Wang, J., Guo, X., 2007. Production of vanillin from waste residue of rice bran oil by Aspergillus niger and Pycnoporus cinnabarinus. Bioresour. Technol. 98, 1115-1119. 


\section{captions for figures and tables}

Table 1. Representative food aroma compounds grouped by chemical classes

Table 2. Production of lactones via biotransformation of fatty acids catalyzed by NCYs

Figure 1. Bioreduction of (Z)-3-hexenal to (Z)-3-hexenol by Wickerhamomyces anomalus

Figure 2. Biotransformation of ricinoleic acid to $\gamma$-decalactone promoted by whole cells of Yarrowia lipolytica

Figure 3. Biotransformation of linoleic acid to $\delta$-decalactone promoted by whole cells of Yarrowia lipolytica

Figure 4. Biotransformation of (-)- $\alpha$-pinene to verbenol by NCYs

Figure 5. Biotransformation of (+)-limonene to perillic acid promoted by whole cells of Yarrowia lipolytica

Figure 6. Biotransformation of (-)-(R)- $\alpha$-phellandrene to 5-p-menthene-1,2-diol promoted by whole cells of Yarrowia lipolytica

Figure 7. Biotransformation pathway of (4S)-carvone by whole cells of NCYs

Figure 8. Biotransformation of (S)-perillaldehyde by whole cells of Kazachstania naganishii

Figure 9. Biotransformation of $\alpha$-methyl-cinnamaldehyde by whole cells of Kazachstania spencerorum

Figure 10. Biotransformation of $(1 R)$-myrtenal by whole cells of NCYs

Figure 11. Biotransformation of geraniol and nerol by whole cells of NCYs

Figure 12. Biotransformation of ketoisophorone by whole cells of NCYs

Figure 13. Biotransformation of 2-methyl-cyclopentenone by whole cells of Kazachstania spencerorum

Figure 14. Biotransformation of L-methionine to methionol

Figure 15. Biotransformation of ferulic acid by whole cells of Debaryomyces hansenii

Figure 16. Biotransformation of eugenol to vanillin and vanillic acid by whole cells of Candida galli 


\begin{tabular}{|c|c|}
\hline Ketones & acetone, 2-butanone, 2-pentanone, 3-pentanone, \\
\hline & $\begin{array}{l}\text { 2-hexanone, 2-heptanone, 2-octanone, 2- } \\
\text { nonanone, 2-undecanone, 2-tridecanone, } \\
\text { acetophenone, 2,3-butanedione, } \\
\text { pentandione, 3-hydroxy-2-butanone, 3-methyl- } \\
\text { 2-butanone, 4-methyl-2-pentanone, } \\
\text { dimethyl-4-hydroxy-3(2H)-furanone, } \\
\text { ketoisophorone }\end{array}$ \\
\hline Aldehydes & $\begin{array}{l}\text { acetaldehyde, propanal, butanal, pentanal, } \\
\text { hexanal, isohexanal, heptanal, octanal, nonanal, } \\
\text { decanal, 2-methylpropanal, 2-methylbutanal, 3- } \\
\text { methylbutanal, propenal, 2-hexenal, (Z)-4- } \\
\text { heptenal, (Z)-2-nonenal, (E)-2-nonenal, (E,E)- } \\
\text { 2,4-nonadienal }\end{array}$ \\
\hline Esters & $\begin{array}{l}\text { methyl acetate, ethyl acetate, 3-octyl acetate, } \\
\text { pentyl acetate, phenethyl acetate, 2-methyl-1- } \\
\text { butyl acetate, 3-methyl-1-butyl acetate, 2- } \\
\text { hydroxyethyl propionate, 2-methyl-2-ethyl-3- } \\
\text { hydroxyhexyl propionate, ethyl butanoate, ethyl } \\
\text { isobutanoate, isobutyl butanoate, propyl } \\
\text { butanoate, ethyl 2-methyl butanoate, ethyl 3- } \\
\text { methyl butanoate, ethyl hexanoate, ethyl } \\
\text { octanoate }\end{array}$ \\
\hline Lactones & $\begin{array}{l}\delta \text {-decalactone, } \gamma \text {-decalactone, } \gamma \text {-butyrolactone, } \\
\delta \text {-dodecalactone,d-octalactone, }(Z)-6 \text {-dodecen- } \\
\delta \text {-lactone }\end{array}$ \\
\hline Acids & $\begin{array}{l}\text { acetic, phenylacetic, propanoic, , butanoic, } \\
\text { isobutanoic, } 2 \text {-methylbutanoic, } \\
\text { methylbutanoic, valeric, caproic, octanoic, } \\
\text { decanoic, }\end{array}$ \\
\hline Alcohols & $\begin{array}{l}\text { ethanol, phenyl ethanol, 2-phenyl ethanol, 2- } \\
\text { methyl propanol, 2-butanol, isobutanol, 2- } \\
\text { methyl butanol, 3-methyl butanol, 2-ethyl } \\
\text { butanol, 1,2-butanediol, 2,3-butanediol, 1- } \\
\text { pentanol, 1-hexanol, 2-heptanol, 2-octanol, 1- } \\
\text { nonanol, 2-nonanol, 1-octen-3-ol, (Z)-1,5- } \\
\text { octadien-3-ol }\end{array}$ \\
\hline Terpenes & $\begin{array}{l}\alpha \text {-pinene, } \beta \text {-pinene, limonene, carvones, } \\
\text { carveols, dihydrocarvones, dihydrocarveols, } \\
\text { perillaldehyde, perillic alcohol, } \alpha \text {-methyl- } \\
\text { cinnamaldehyde, myrtenal, geraniol, nerol }\end{array}$ \\
\hline Phenols & vanillin, vanillic acid, benzaldehyde \\
\hline Sulphur compounds & $\begin{array}{l}\text { methanethiol, dimethyl disulphide, dimethyl } \\
\text { trisulphide, S-methylthioacetate and S- } \\
\text { methylthiobutyrate, methionol }\end{array}$ \\
\hline
\end{tabular}

Tab. 1 


\begin{tabular}{|c|c|c|c|}
\hline Species & Substrate & Product(s) & References \\
\hline $\begin{array}{c}\text { Lindnera saturnus } \\
\text { (formerly Hansenula } \\
\text { saturnus) }\end{array}$ & Ricinoleic acid & 3-hydroxylactone, decen-4-olides & Waché et al. 2001 \\
\hline Yarrowia lipolytica & Ricinoleic acid & 3-hydroxylactone, decen-4-olides & Waché et al. 2001 \\
\hline Yarrowia lipolytica & Ricinoleic acid & $\gamma$-decalactone & Waché et al. 2003 \\
\hline Candida albicans & Linoleic acid & $\gamma$-nonalactone & Feron and Waché 2005 \\
\hline Candida tropicalis & Linoleic acid & $\gamma$-nonalactone & Feron and Waché 2005 \\
\hline $\begin{array}{c}\text { Yarrowia lipolytica } \\
\text { (formerly Candida }\end{array}$ & Linoleic acid & $\gamma$-nonalactone & Feron and Waché 2005 \\
\hline
\end{tabular}

Tab. 2 